\title{
Toy soldier syndrome: A consequence of parental cognitive dissonance
}

Yifrah Kaminer, MD, and Liah Kaminer, MA

Editor's note: Readers' Forum is a department for correspondence from readers that is not in response to articles published in CURRENT PSYCHIATRY. All submissions to Readers' Forum undergo peer review and are subject to editing for length and style. For more information,contact letters@currentpsychiatry.com.

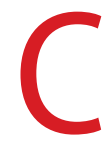

hildhood and adolescence are periods with marked psychobehavioral development of the brain. The sense of self, identity, and role are established. This process is not without risk because brain regions governing reward, impulsivity, and sensation-seeking are relatively more developed and influential than higher-order cognitive regions regulating behavioral inhibition, decision-making, and planning, which continue to mature into one's early to mid-20s. Consequently, while the developing brain is "under construction" by forging new pathways and taking advantage of its immense neuroplasticity, it is also prone to psychological insults under exposure to stressful events, attitudes, and behaviors, including those that can arise in the family. ${ }^{1}$

Most people would agree that there is no stronger emotion than parental love. The origins of this powerful biobehavioral bonding with a child have been attributed to maternal release of oxytocin, known colloquially as the "love hormone," during the birthing process, and to both biological parents experiencing psychosocial attachment with their infant. Therefore, common sense dictates that parents would do anything to protect their offspring, and that no parent would deliberately behave in a manner that harms their child.

Common sense notwithstanding, reports of both child neglect and abuse are common. States have established agencies to protect children from their own parents. The answers to the question "Whose kids are they?" and under what circumstances the state has the authority to warn or reprimand parents, or even temporarily or permanently separate minors from their parents, are complex and vary by state.

In this commentary, we describe harmful actions committed by parents with the intention of protecting the impressionable minds of their children from malevolent forces or intrusive and unhealthy ideas. Second, we examine how to protect a minor from parental actions that are well-meaning but potentially harmful.

\section{Parent-child communication}

Delusional family interactions. Originally described in 1877 as "folie à deux," madness is an extreme and uncommon parental psychiatric condition harmful to a child's mental health. It is primarily characterized by parental-initiated delusions shared with the child that are typically persecutory and attributed to danger from vengeful folks or grandiose in nature. The question of whether the "folie" or "madness" is contagious arises due to the propensity of the child to adopt these delusions under an imposed insular or restrictive environment. Separating the child from the environment dominated by the delusional adult usually is sufficient
Dr. Kaminer is Professor Emeritus, Department of Psychiatry and Department of Pediatrics, University of Connecticut School of Medicine, Farmington, Connecticut. Ms. Kaminer is a Mental Health Specialist, McLean Hospital, Belmont, Massachusetts.

\section{Disclosures}

The authors report no financial relationships with any companies whose products are mentioned in this article, or with manufacturers of competing products.

doi: 10.12788/cp.0181

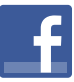

Discuss this article at www.facebook.com/ MDedgePsychiatry 


\section{Clinical Point}

\section{Communicate to parents the importance of not forcing their children to join their battles}

to reverse the symptoms due to reality testing.

Normative familial communication. In contrary to a delusional familial interaction, normative family traditions and values are a unifying psychosocial force and a source of bonding and loyalty from an early age. A ubiquitous example is the support of a local sports team, and the emotional turmoil associated with the team's wins and losses, accompanied by "hating" a rival. These family rituals are commonly devoid of emotional negative consequences for an impressionable young mind unless the child is exposed to unsportsmanlike emotional, verbal, or aggressive behavior by an adult at home in front of the television or in the stands at a game.

Unfortunately, the "love-hate" dichotomy rooted in family-generated traditions of loyalty is becoming more evident in today's turbulent sociopolitical environment. Children and young adolescents are not prepared to cope with the stressful effects of repeated exposure to intense conflictual events at home when parents adopt opposing sociopolitical ideologies. Furthermore, a parent might intentionally expose their child to emotionally conflictual circumstances in the name of a perceived value that might create and exacerbate stress, fear, and self-loathing. Ironically, by doing what a parent believes is right for their child, they might be transforming the child without their consent into a variant of a "toy soldier by proxy." Such a child is a tool expected to follow the parental pathway and belief system without questioning, or even having the cognitive ability to do so, given their ongoing bio-behavioral and moral developmental phase. ${ }^{3}$

This new normative exposure to conflictual situations at the will of the parent is not only limited to watching them remotely but also may include participating in what is meant to be a peaceful protest or march. As we all witnessed in 2020, such events can easily deteriorate into unsafe environments rife with lawlessness and uncontrolled violence. This has included clashes between opposing groups who are matched in zeal and conviction, as well as opposition to or endangerment by law enforcement personnel trying to restore order by force. This is not where a responsible parent should take their child. Furthermore, there is the danger of loss of privacy of children exposed by media following their participation in public activity. This may lead to hate mail as that would further confuse and jeopardize a peaceful lifestyle, which is highly desirable for a developing child.

Cognitive dissonance. Have these parents temporarily allowed the limbic system to trump the restraints of the prefrontal cortex, as exhibited by an impulsive and risky behavior driven by poor insight? Have these parents thoughtfully weighed the balance between the merit of a child's exposure to such conflictual circumstances and the peril of negative emotional consequences? This is illustrated by a mother who has been taking her preadolescent son to demonstrations regularly because "I want him to see how democracy works."

Might this be a case of cognitive dissonance (CD) that amounts to unwitting mental child abuse if it happens repeatedly? According to the CD theory, there is a tendency to seek consistency between cognitions (eg, beliefs, opinions) and attitudes or behaviors. Inconsistency between these variables is termed "dissonance." The importance attached to the dissonant belief affects the severity of the dissonance. The dissonance occurs when a parent must choose between 2 incompatible beliefs or actions. A classic demonstration of $\mathrm{CD}$ is when an adult requests that an adolescent follows his instructions (eg, "do not smoke or drink alcohol"), yet the adult does not act accordingly (eg, they smoke or drink). Role modeling demonstrated by such a discrepancy is a cause of confusion in the child. In terms of this article, the $\mathrm{CD}$ is between what the parent believes is an important learning experience by exercising the perceived right to pass to the child the parental value system 
vs compromising the protection of the child by exposing them to the potential negative consequences of a risky situation.

\section{What can parents and therapists do?}

Usually, parents mean well. It is important to communicate to parents the importance of refraining from forcing their children to join their battles. Calculating risks based on an intuitive approach is flawed because doing so is based on beliefs and emotions that originated in the limbic system ("I feel that"...) and are neither precise nor accurate. ${ }^{6}$ Teaching our youth in the school system how to think (eg, the science of logic and history of science) vs what to think (ie, indoctrination) is a key to healthy cognitive development. Furthermore, children need to have the time, space, and opportunities (learning moments) to develop this capacity. It is not until approximately age 16 that abstract thinking capabilities are developed. Cognitive dissonance can be eliminated by reducing the valence of the conflicting beliefs or by removing the conflicting attitude or behavior.

As parents and as mental health professionals, we should carry the necessary burden of responsibility to prevent the risk of "lost childhood" due to parental emotional zeal and righteousness that lead to early exposure to damaging adversity. We cannot afford to turn our children into exploitable tools (ie, toy soldiers) in conflicts they do not fully grasp.

\section{References}

1. Bagot KS, Kaminer Y. Harm reduction for youth in treatment with substance use disorders: one size does not fit all. Curr Addict Rep. 2018;5:379-385.

2. Arnon D, Patel A, Tan GM. The nosological significance of Folie à Deux: a review of the literature. Ann Gen Psychiatry. 2006;5:11.

3. Kohlberg L. The philosophy of moral development: the nature and validity of moral stages. Harper \& Row; 1984

4. Festinger L. A theory of cognitive dissonance. Stanford University Press; 1957.

5. Festinger L. Cognitive dissonance. Sci Am. 1962;207:93-102.

6. Henderson SW, Gerson R, Phillips B. What is "high risk" and what are we actually supposed to do about it? J Am Acad Child Adolesc Psychiatry. 2019;58(6): 561-564.

\section{Clinical Point}

We cannot afford
to turn our children
into exploitable tools
in conflicts they do
not fully grasp

We cannot afford to turn our children in conflicts they do not fully grasp 